\title{
AN UNCOMMON COMPLICATION OF A COMMON DISORDER: PNEUMOTHORAX, PNEUMOMEDIASTINUM AND SUBCUTANEOUS EMPHYSEMA COMPLICATING ACUTE SEVERE ASTHMA: A CASE REPORT
}

Urvinderpal Singh ${ }^{1}$, Aditi², Vidhu Mittal ${ }^{3}$

\section{HOW TO CITE THIS ARTICLE:}

Urvinderpal Singh, Aditi, Vidhu Mittal. "An Uncommon Complication of a Common Disorder: Pneumothorax, Pneumomediastinum and Subcutaneous Emphysema Complicating Acute Severe Asthma: A Case Report". Journal of Evolution of Medical and Dental Sciences 2014; Vol. 3, Issue 21, May 26; Page: 5680-5684, DOI: $10.14260 /$ jemds/2014/2648

ABSTRACT: Pneumomediastinum (air in the mediastinum) was first described as a complication of trauma in 1819 by Laennec. Although subcutaneous emphysema, pneumothorax and pneumomediastinum are relatively uncommon, but are important complications of bronchial asthma. Their sudden and usually unexpected onset may herald an emergency. We are reporting a case of a 72 year old male presenting with pneumothorax, pneumo- mediastinum and subcutaneous emphysema as a complication of acute severe asthma.

KEYWORDS: Pneumomediastinum, Bronchial Asthma, Pneumothorax.

INTRODUCTION: Extravasation of air in extra pulmonary tissues, a complication of many diseases and surgical procedures may manifest as pneumomediastinum, pneumopericardium or pneumothorax. The term pneumomediastinum, first introduced into medical literature by Hamman in $1939^{1}$ which means the presence of air within the mediastinum, while subcutaneous emphysema refers to the presence of air in subcutaneous tissue and this may involve the face, neck or trunk. Mcgovernet $\mathrm{al}^{2}$ reported the first definitive case of asthma complicated by subcutaneous emphysema in 1850. Bronchial constriction and cough during severe asthma exacerbation are included among the various precipitating events triggering a strong Valsalva manoeuvre, creating the pressure difference needed for its genesis. ${ }^{3}$

Although pneumothorax, subcutaneous emphysema and pneumomediastinum are relatively uncommon, they are important complications of asthma. Their sudden and usually unexpected onset, have the hallmark of an emergency. 4

We present a case of pneumothorax, pneumomediastinum and subcutaneous emphysema complicating acute severe asthma in a 72 year old male in order to sensitize clinicians about the occurrence of this rare complication of bronchial asthma.

CASE REPORT: A 72 year old male patient, known case of bronchial asthma presented to us in the emergency with complaints of progressive breathlessness and cough for 1 week. There was no history of orthopnea and paroxysmal nocturnal dyspnea. The cough was episodic and dry in nature. Patient was a nonsmoker without any history of drug abuse or exposure of pets. Patient was taking some inhalation therapy for bronchial asthma off and on. On examination, he was severely dyspneic with accessory muscles of respiration in use and was unable to speak a sentence. Pallor was observed but no cyanosis was seen.

Blood pressure of $140 / 90 \mathrm{~mm}$ of mercury and pulse rate of 140 per minute with respiratory rate of 43/minute was observed. Saturation of oxygen was 85\% @ room air. On auscultation, 
extensive rhonchi were audible in both lung fields. Examination of other systems was essentially normal. Laboratory findings showed white blood cell (WBC) count of 6, 800 cells $/ \mathrm{mm}^{3}$ with $66 \%$ polymorphonuclear neutrophils, 30\% lymphocytes and 2\% eosinophils. Electrolyte levels, liver function test results and electrocardiogram (ECG) were normal. X ray of chest was also normal. He was diagnosed as a case of acute severe asthma and managed accordingly.

He showed marked improvement with oxygen therapy (40\%), nebulisation with levosalbutamol every 2 hourly and prednisolone $40 \mathrm{mg}$ per oral. On the first night of admission, patient had a severe bout of coughing which led to deterioration of his condition with complaints of severe pain in the chest, increased breathlessness and fall in oxygen saturation. On examination, apart from tachycardia and tachypnea there were no other abnormal findings. Repeat ECG was also normal ruling out any cardiac event.

By morning, on examination a crunchy sound was heard synchronous with the heart beats in the apical region along with diminished breath sounds in right lung. Thus suspecting some serious complication, a Contrast Enhanced Computed Tomography (CECT) of chest was done which revealed right sided pneumothorax, subcutaneous emphysema with pneumomediastinum. (Fig. 1, Fig. 2)

As his pneumothorax was minimal, he was managed conservatively and was administered high concentration oxygen therapy (60\%) along with his management of bronchial asthma but before his improvement could be assessed, he left against medical advice and was lost to follow up.

DISCUSSION: The term primary spontaneous pneumomediastinum is used to describe the presence of air in the mediastinal tissue in the absence of predisposing disease while secondary spontaneous pneumomediastinum is used where the leakage of air in the mediastinal tissue has resulted from a co-existing structural abnormality which can be in the lung or mediastinum.5, 6,7 Our patient had Pneumothorax, pneumomediastinum and subcutaneous emphysema as a complication of acute severe asthma.

pneumomediastinum can occur as a result of alveolar rupture and air may then track along interstitial and vascular supporting tissues until it gets in to the mediastinum. Air may also track to the neck and the rest of the body resulting in subcutaneous emphysema or into the pleural space causing pneumothorax. ${ }^{4}$

Common symptoms of these complications are chest pain and worsening of breathlessness. Whereas subcutaneous emphysema causes crepitus on palpation of the affected body region, pneumomediastinum characteristically gives a positive Hamman sign (crunching or clicking noise heard synchronously with the heart beat on auscultation and best heard in the left lateral decubitus position) when it is clinically significant. ${ }^{8}$ Chest pain, breathlessness and diminished oxygen saturation as seen in our case, along with any of these clinical signs should heighten suspicion of such a complication. ${ }^{9}$

Although pneumothorax is easily diagnosed on chest X-ray, pneumomediastinum is manifested on CXR by lucent streaks or bubbles of gas that outline mediastinal structures, elevate the mediastinal pleura, and often extend into the neck or chest wall. Mediastinal gas outlining the superior surface of the diaphragm and separating it from the heart results in the continuous diaphragm sign. ${ }^{2}$ Identifying these signs are important because this condition presents with subtle signs and can be life threatening in a few cases ${ }^{10}$. Although the symptom-complex of asthma in 
association with pneumothorax, subcutaneous emphysema and pneumomediastinum as seen in our case is rare but there are a few case reports of such complications of bronchial asthma. ${ }^{3,4,5,11}$

Taking into consideration the benign nature of this entity, only cases, where the diagnosis is in question, the underlying disease needs specific treatment or the possibility of an organ perforation cannot be ruled out, should be considered for further diagnostic workup and admission. ${ }^{10}$ Administration of high concentration of oxygen may enhance faster absorption of air from extrapulmonary tissues while needle aspiration or surgical decompression may be useful if mediastinal structures are compressed.11

Often, the amount of air is minimal, and no chest tube insertion is required. When severe tension symptoms occur, insertion of chest tube under a water seal for pneumothorax may be needed. Tracheostomy may be required for severe tension complications of pneumomediastinum. Although pneumomediastinum rarely becomes physiologically significant, in rare instances it can produce life-threatening cardiovascular collapse.

Pneumomediastinum subsides uneventfully in the vast majority of instances once the precipitating event or process has resolved. Recurrence of spontaneous mediastinal emphysema is unusual, although it has been described in both children and adults. ${ }^{1}$

To summarize, extravasation of air manifested as pneumothorax pneumomediastinum, and subcutaneous emphysema in this case constitutes a rare but important complication of acute severe asthma, which is more often than not amenable to conservative management and the physicians should be aware of these rare complications of acute severe asthma which might be life threatening.

\section{BIBLIOGRAPHY:}

1. Park DR, Vallières E. Pneumomediastinum and Mediastinitis. In: Mason RJ, editor. Murray and Nadel's Textbook of Respiratory Medicine, 4th ed. Philadelphia: Elsevier Saunders; 2005. 2039-49.

2. Bejvan MS, Godwin DJ. Pneumomediastinum: Old Signs and New Signs. AJR 1996; 166: 51041-8.

3. Pala G, Pignatti P, Moscato G. Pneumomediastinum is a Possible Acute Complication of Severe Occupational Asthma. Iran J Allergy Asthma Immunol 2012; 11:77-9.

4. Egbagbe EE, Elusoji SO. Pneumomediastinum and Subcutaneous Emphysema associated with Asthma Exacerbation. J Pak Med Assoc. 2006; 56: 287-9.

5. Inna K, Bartolome RC. Pneumomediastinum in a 63 year old woman with Asthma Exacerbation. Chest 2000; 117: 1778-81.

6. Macklin MT, Macklin CC. Malignant interstitial emphysema of the lungs and mediastinum as an important occult complication of many respiratory diseases and other conditions: an interpretation of the clinical literature in the light of laboratory experiment. Medicine (Baltimore), 1944; 23:281.

7. McMahon DJ. Spontaneous pneumomediastinum. Am J Surg 1976; 131:550

8. Hamman L. Spontaneous mediastinal emphysema. Bull Johns Hopkins Hosp 1939; 64:1-21

9. Sood RG, Sharma S, Mokta JK, Jhobta A, Bhatia V, Panda P. Pneumothorax and Pneumomediastinum in a Sputum Positive Tuberculosis Patient: The Continuous Diaphragm Sign. Online J Health Allied Scs. 2012; 11:16.

10. Stack A.M, Caputo GL. Pneumomediastinum in childhood asthma. Pediatr Emerg Care. 1996; 12:98-101. 


\section{CASE REPORT}

11. Akinyemi RO, Ogah OS, Akisanya CO, Timeyin AO, Akande KO, Durodola A et al. Case report: Pneumomediastinum and Subcutaneous Emphysema Complicating Acute Exacerbation of Bronchial Asthma. Annals of Ibadan Postgraduate Medicine 2007; 5:77.

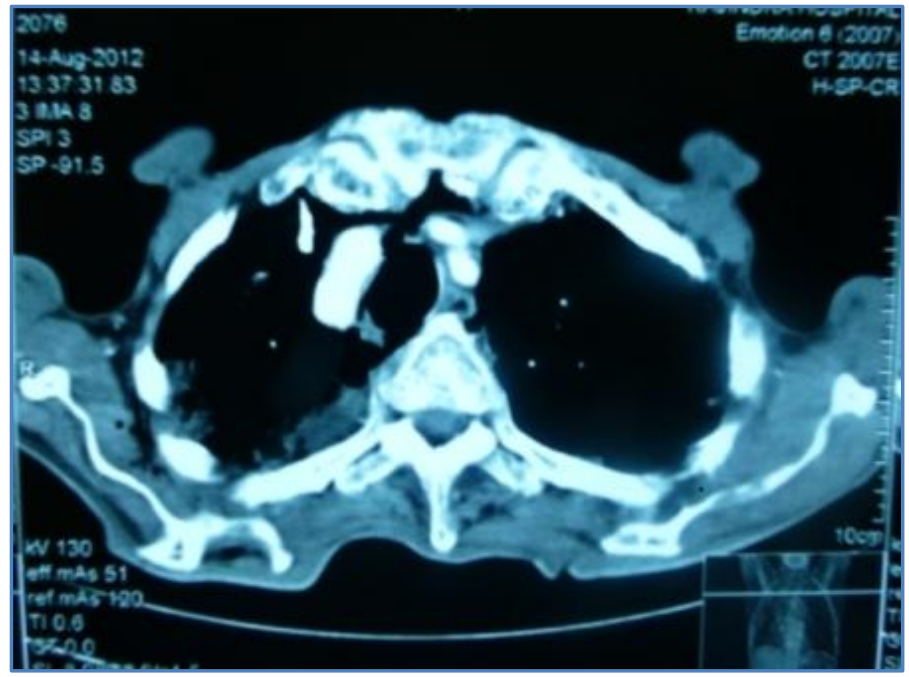

Fig. 1: (p1000844): CECT chest showing subcutaneous emphysema.

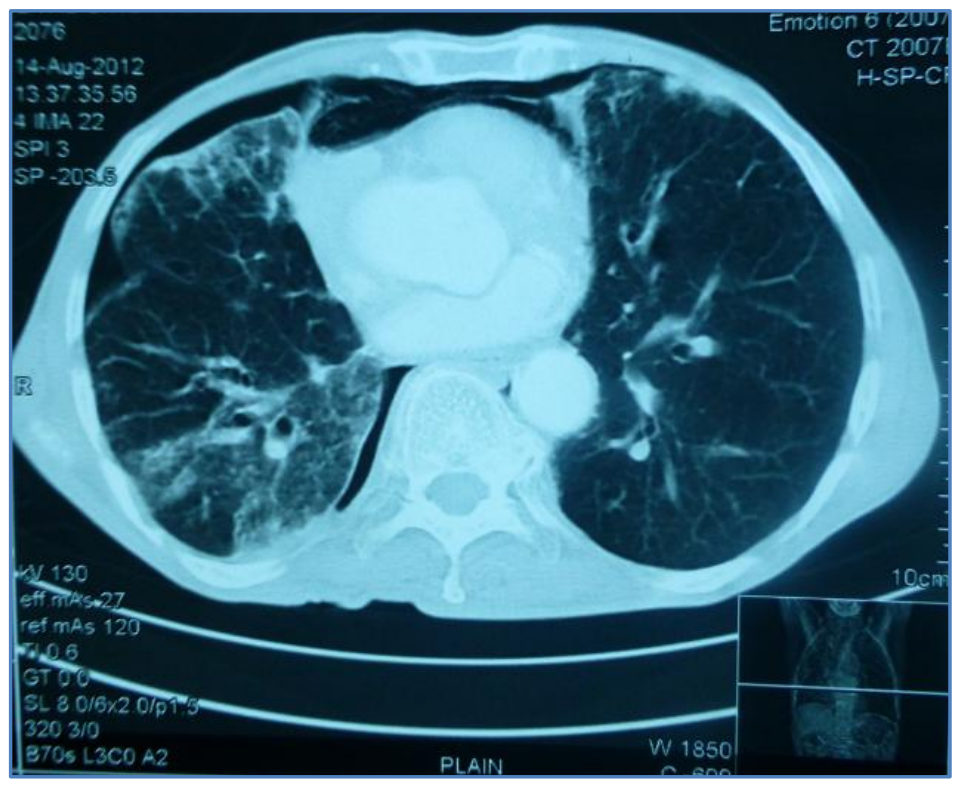

Fig. 2: (p1000845): CECT chest showing right sided pneumothorax and pneumomediastinum 


\section{CASE REPORT}

\section{AUTHORS:}

1. Urvinderpal Singh

2. Aditi

3. Vidhu Mittal

\section{PARTICULARS OF CONTRIBUTORS:}

1. Associate Professor, Department of Chest and Tuberculosis, GMC, Patiala.

2. Post Graduate Student, Department of Chest and Tuberculosis, GMC, Patiala.

3. Post Graduate Student, Department of Chest and Tuberculosis, GMC, Patiala.

\section{NAME ADDRESS EMAIL ID OF THE} CORRESPONDING AUTHOR:

Dr. Urvinderpal Singh,

Associate Professor, \#22, Baba Sri Chand Marg, Opposite Government Press,

Sirhind Road, Patiala-147001, (P B).

Email: singhurvinderpal@hotmail.com

Date of Submission: 02/05/2014.

Date of Peer Review: 03/05/2014.

Date of Acceptance: 13/05/2014.

Date of Publishing: 20/05/2014. 